\title{
MÉTODOS DE SUPERAÇ̃̃O DE DORMÊNCIA EM SEMENTES DE CROADA (Mouriri elliptica Mart)
}

\author{
Dormancy breaking methods in croada (Mouriri elliptica Mart) seeds
}

\author{
Jaqueline Martins Vasconcelos ${ }^{1}$, Thálita Vaz Cardoso ${ }^{1}$, Juliana de Fátima Sales ${ }^{2}$, Fabiano Guimarães Silva ${ }^{1}$, \\ Sebastião Carvalho Vasconcelos Filho ${ }^{3}$, João das Graças Santana ${ }^{1}$
}

\begin{abstract}
RESUMO
Sementes de croada (Mouriri elliptica Mart.) Melastomataceae, espécie frutífera nativa do cerrado, foram submetidas aos seguintes tratamentos, visando a superação de dormência: pré-resfriamento a $5^{\circ} \mathrm{C}$ por 7 dias; pré-aquecimento em estufa com circulação de ar a $40^{\circ} \mathrm{C}$ por 7 dias; escarificação química em ácido sulfúrico concentrado por 5 e 15 minutos; imersão em água fervente por 5 e 15 minutos; imersão em ácido giberélico a 100 e $200 \mathrm{mg} \mathrm{L}^{-1}$ por 48 horas; imersão em água destilada por 24 e 48 horas; escarificação mecânica com lixa no 80 na parte superior e oposta ao eixo embrionário e testemunha (sementes sem tratamento prévio). Quatro repetições de quinze sementes foram colocadas para germinar sobre papel umedecido com água destilada ou nitrato de potássio a $0,2 \%$, em temperatura de $30^{\circ} \mathrm{C}$ em presença de luz. Foram realizadas contagens diárias do $2^{\circ}$ dia após a implantação do experimento até a estabilização da porcentagem de germinação, que acorreu no $60^{\circ}$ dia. A germinação foi mais rápida em sementes préembebidas em ácido giberélico (em substrato umedecido com água ou com solução de nitrato de potássio 0,2\%), pré-embebidas em água por 24 horas, em substrato umedecido com água, e pré-embebidas em água por 48 horas ou escarificadas mecanicamente e colocadas para germinar em substrato umedecido com água. Taxas de germinação mais elevadas ocorreram em sementes pré-embebidas em ácido giberélico a 100 ou $200 \mathrm{mg} \mathrm{L}^{-1}$, em substrato umedecido com solução de nitrato de potássio $0,2 \%$.
\end{abstract}

Termos para indexação: Melastomataceae, Mouriri elliptica Mart., germinação, frutífera nativa do cerrado.

\section{ABSTRACT}

Croada seeds (Mouriri elliptica Mart.) Melastomataceae, a fruit-bearing species native of the cerrado (savannah-like vegetation), were submitted to the following dormancy breaking methods: pre-cooling at $5^{\circ} \mathrm{C}$ for 7 days; pre-heating in a oven air circualtion at $40^{\circ} \mathrm{C}$ for 7 days; chemical escarification in concentrated sulfuric acid for 5 and $15 \mathrm{~min}$; soaking in boiling water for 5 and 15 min; soaking in gibbereli acid at 100 and $200 \mathrm{mg} \mathrm{L}^{-1}$ for 48 hours; soaking into distilled water for 24 and 48 hours; mechanical escarification with a sandpaper number 80 at teh upper aprt and opposed to the embryonary axis and control (seeds without any previous treatment). The seeds were put to germinate on a "germitest" type paper moistened with destilled water or $0.2 \%$ potassiun nitrate. Daily counts between the 2nd day after the establishment of the experiment till the stabilization, which took place on the $60^{\text {th }}$ day, were performed. Seeds germinated faster when they were pre-soaked in gibberelic acid, independent of if placed to germinate on a water-moistened substrate or with a soultion of $0.2 \%$ potassiun nitrate, pre-soaked into water for 24 hours, on a water-moistened substrate, or independent of the substrate, and, pre-soaked into water for 48 hours or mechanical escarification and put to germinate on a water-containing substrate. Higher germination rates occurred in seeds pre-soaked into 100 or $200 \mathrm{mg} \mathrm{L}^{-1}$ gibberelic acid, on a substrate moistend with a $0.2 \%$ potassiun nitrate containing solution.

Index terms: Melastomataceae, Mouriri elliptica Mart., germination, fruit-bearing plant native to the cerrado.

(Recebido em 12 de setembro de 2008 e aprovado em 11 de maio de 2009)

\section{INTRODUÇÃO}

O cerrado brasileiro ocupa aproximadamente $85 \%$ do Planalto Central do Brasil e constitui a segunda maior formação vegetal do país, superada apenas pela Floresta Amazônica (Pivello, 2007). Estende-se pelos estados de Mato Grosso, Mato Grosso do Sul, Rondônia, Goiás, Tocantins, Maranhão, Piauí, Bahia, Minas Gerais, São Paulo e Distrito Federal (Empresa Brasileira de Pesquisa Agropecuária - Embrapa, 1987).

A Croada (Mouriri elliptica Mart.) - Melastomataceae, também conhecida como croadinha ou coroa-de-frade, é uma planta arbórea com cerca de 4 a $6 \mathrm{~m}$ de altura, típica do Cerrado Brasileiro. É imprescindível que os cultivos de plantas nativas sejam iniciados com eficiência e, tendo em vista a rápida ocupação agrícola no bioma cerrado e a exploração extrativista, torna-se indispensável a descoberta de técnicas que superem a dormência de suas sementes para a produção de mudas, pois algumas espécies frutíferas do cerrado apresentam problemas como a germinação lenta e desuniforme (Silva et al., 2001).

${ }^{1}$ Centro Federal de Educação Tecnológica de Rio Verde/CEFETRV - Rio Verde, GO

${ }^{2}$ Centro Federal de Educação Tecnológica de Rio Verde/CEFETRV - Rodovia Sul Goiana - km 01 - Zona Rural - $75901-970$ - Rio Verde, GO juliana.sales@pq.cnpq.br

${ }^{3}$ Universidade de Rio Verde/FESURV - Rio Verde, GO 
A dormência de sementes pode ser definida como a ausência de germinação em sementes viáveis, mesmo com todas as condições ambientais satisfatórias para o crescimento (água, oxigênio, temperatura e ausência de inibidores).

A dormência tegumentar caracteriza-se pela dificuldade de absorção de água pela semente, o que a impede de iniciar a hidratação e, consequentemente, restringe os processos físicos e as reações metabólicas básicas da germinação. As sementes de croada apresentam tegumento duro e não foram encontrados estudos sobre a germinação dessa espécie. As espécies florestais são especialmente ricas em exemplos desse tipo de dormência (Borges et al., 2004).

Sementes de Leucaena leucocephala (Lam.) de Wit apresentaram porcentagens de germinação acima de $90 \%$, quando imersas durante 15 ou 20 minutos em ácido sulfúrico (Teles et al., 2000); sementes de Tachigalia multijuga pré-embebidas com ácido sulfúrico por 20 minutos apresentaram superação da dormência (Borges et al., 2004); e sementes de Stryphnodendron adstringens (Mart.) Coville e de Stryphnodendron polyphyllum Mart. pré-embebidas por 45 a 90 minutos e 45 a 105 minutos, respectivamente, apresentaram superação de dormência (Martins \& Silva, 2008), bem como Dimorphandra mollis Benth. pré-embebidas durante 45 a 90 minutos; entretanto, tratamento por período superior a 90 minutos resultou em decréscimo marcante na viabilidade (Hermansen et al., 2000). Por outro lado, em sementes de Ormosia nitida Vogel tratadas com ácido sulfúrico, Lopes et al. (2006) observaram aumento acentuado na porcentagem de sementes deterioradas, evidenciando que esses tratamentos, sempre que possível, devem ser evitados, principalmente pelo grau de periculosidade que oferecem, os quais, apesar de superarem o fenômeno da dormência, aumentam significativamente a porcentagem de sementes deterioradas, culminando com alta incidência de fungos e bactérias, corroborando os resultados observados no presente trabalho. Para outras espécies, mesmo em tempo de exposição curtos (60 segundos), o ácido sulfúrico não foi efetivo na promoção da germinação, tornando-se prejudicial, como ocorrido para Satureja montana L. (Boscagli \& Sette, 2001).

A germinação de sementes pode exigir giberelinas para ativar o crescimento vegetativo do embrião, o enfraquecimento do endosperma, culminando com a quebra da dormência (Taiz \& Zeiger, 2004). O trabalho de Cruz et al. (2007) com Schizolobium amazonicum Huber ex Ducke demonstrou que a superação da dormência foi alcançada com a escarificação mecânica. Resultados semelhantes foram alcançados com tratamentos feitos com escarificações mecânicas com lixa número 60 para sementes de Ormosia nitida (Lopes et al., 2006). Em Caesalpinia ferrea Mart., a escarificação mecânica com lixa ${ }^{\circ} 40$ foi um método eficiente para superação da dormência da semente (Lima et al., 2006).

Objetivou-se, no seguinte trabalho, identificar métodos para superar a dormência de sementes de croada (Mouriri elliptica Mart.).

\section{MATERIAL E MÉTODOS}

O experimento foi realizado no Laboratório de Sementes do Instituto Federal Goiano - Campus Rio Verde. As sementes de croada foram obtidas de frutos maduros coletados no povoado de Planalto Verde, Município de Montividiu-GO, latitude (S) - 17 ${ }^{\circ}$ 19.201'; longitude (W) $-51^{\circ} 33,500^{\prime}$ e atitude de $982 \mathrm{~m}$. Os frutos ficaram armazenados no laboratório, em temperatura média de $25^{\circ} \mathrm{C}$, por duas semanas. Após esse período, as sementes foram extraídas dos frutos utilizando despolpadeira (Processador Ker DOD 1.5, Tortuga), lavadas em água corrente para a eliminação de resíduos, colocadas sobre papel toalha em temperatura ambiente por, aproximadamente, 30 minutos para retirar o excesso de umidade superficial e, em seguida, tratadas com carboxina + tiram $\left(200+200 \mathrm{~g} \mathrm{~L}^{-1}\right)$, na concentração de $300 \mathrm{~mL}$ de fungicida para $100 \mathrm{~kg}$ de sementes.

As sementes foram submetidas aos seguintes tratamentos de superação de dormência: pré-resfriamento em substrato umedecido a $5^{\circ} \mathrm{C}$ por 07 dias; préaquecimento em estufa com circulação de ar a $40^{\circ} \mathrm{C}$ por sete dias; escarificação química por imersão das sementes em ácido sulfúrico $\left(\mathrm{H}_{2} \mathrm{SO}_{4}\right)$ P.A. (98\%), por 5 e 15 minutos, seguida de lavagem em água corrente e secagem sobre papel à temperatura ambiente por uma hora; e imersão em água fervente por 5 e por 15 minutos - imersão das sementes em água pelo tempo previsto, cuja temperatura inicial foi de $87^{\circ} \mathrm{C}$ e finais, de $71^{\circ} \mathrm{C}$, para 5 minutos, e de $56^{\circ} \mathrm{C}$, para 15 minutos. Decorrido o tempo estabelecido para cada tratamento, 5 e 15 minutos, as sementes foram lavadas em água corrente; colocadas para secar em temperatura ambiente por uma hora; imersas em ácido giberélico a 100 e $200 \mathrm{mgL}^{-1}$ por 48 horas; imersas em água destilada em temperatura ambiente por 24 e 48 horas; e tiveram escarificado seu tegumento com uma lixa $n^{\circ} .80$, na parte superior e oposta ao eixo embrionário; a testemunha constituiu-se de sementes intactas, sem tratamento.

As sementes foram colocadas para germinar em caixas plásticas $(11,0 \times 11,0$ × 3,5 cm), sobre 2 folhas de 
papel umedecidas a 2,5 vezes o peso do substrato seco em água ou solução de $\mathrm{KNO}_{3}(0,2 \%)$ e mantidas a $30^{\circ} \mathrm{C}$, em presença de luz. Foram consideradas germinadas as sementes que apresentaram início de protrusão da radícula. O experimento foi encerrado aos 60 dias após implantação.

Foram realizadas contagens diárias, avaliando-se a porcentagem de germinação e o IVG (Índice de Velocidade de Germinação). O IVG foi calculado mediante a contagem diária da germinação e aplicando-se metodologia descrita por Maguire (1962).

O delineamento experimental foi em blocos casualizados em esquema fatorial 2 x 12, com 2 (água ou solução contendo $\mathrm{KNO}_{3} 0,2 \%$ ), e 12 (métodos de superação de dormência), em 4 blocos (com 15 sementes cada), totalizando 96 unidades experimentais. Os resultados foram submetidos à análise de variância e as médias foram comparadas pelo teste de Scott-Knott, a $5 \%$ de probabilidade, utilizando-se o programa SAEG (Sistema de Análises Estatísticas e Genéticas) (Ribeiro Júnior, 2001).

\section{RESULTADOS E DISCUSSÃO}

As sementes de croada iniciaram a germinação a partir do $8^{\circ}$ dia, a qual se estabilizou no $60^{\circ}$ dia. Sementes não tratadas (testemunha) apresentaram germinação média de $43,38 \%$, confirmando a observação de que a espécie estudada apresenta dormência.

Solução de $\mathrm{KNO}_{3}$ a $0,2 \%$ no papel de germinação não exerceu efeito no vigor das sementes (Tabela 1). Os procedimentos de pré-embebição de sementes em ácido giberélico, água ou escarificação mecânica demonstraram eficiência em reduzir o tempo de germinação se comparados ao uso de sementes sem tratamento prévio. Ferreira \& Gentil (2006) encontraram resultados superiores na velocidade de germinação em sementes de tucumã pré-embebidas em água. Os autores afirmam que para as sementes dessa espécie, quanto maior o tempo de embebição em água, menor o tempo médio para a germinação das sementes. O pré-resfriamento das sementes não exerceu efeito se comparado à testemunha. $\mathrm{O}$ pré-aquecimento e a pré-embebição em $\mathrm{H}_{2} \mathrm{SO}_{4}$ ou em água fervente reduziram o vigor das sementes. Os tratamentos com ácido sulfúrico apresentaram 51\% de sementes mortas, resultado também observado por Carmona et al. (1986) com sementes de Stylosanthes macrocephala M. B. Ferreira \& S. Costa.

Os tratamentos analisados influenciaram a porcentagem de germinação (Tabela 2 ). O pré-resfriamento não exerceu influência sobre sementes colocadas em papel umedecido com água, quando comparado ao controle. Os métodos de superação de dormência envolvendo pré-

Tabela 1 - Índice de velocidade de germinação de sementes de Croada (Mouriri elliptica Mart.), submetidas a diferentes métodos de superação de dormência e semeadas em substratos umedecidos com água ou com solução de $\mathrm{KNO}_{3}(0,2 \%)$.

\begin{tabular}{lcc}
\hline \multicolumn{1}{c}{ Métodos de superação de dormência } & \multicolumn{2}{c}{ Substrato } \\
\cline { 2 - 3 } & $\mathrm{H}_{2} \mathrm{O}$ & $\mathrm{KNO}_{3}$ \\
\hline Pré-resfriamento $\left(5^{\circ} \mathrm{C}\right.$ por 07 dias) & $0,26 \mathrm{Ba}^{\mathrm{z}}$ & $0,38 \mathrm{Ca}$ \\
Pré-aquecimento (40 $\mathrm{C}$ por 07 dias) & $0,01 \mathrm{Ca}$ & $0,00 \mathrm{Da}$ \\
Pré-embebição em $\mathrm{H}_{2} \mathrm{SO}_{4}$ por 05 minutos & $0,00 \mathrm{Ca}$ & $0,00 \mathrm{Da}$ \\
Pré-embebição em $\mathrm{H}_{2} \mathrm{SO}_{4}$ por 15 minutos & $0,00 \mathrm{Ca}$ & $0,00 \mathrm{Da}$ \\
Pré-embebição em água fervente por 05 minutos & $0,01 \mathrm{Ca}$ & $0,00 \mathrm{Da}$ \\
Pré-embebição em água fervente por 15 minutos & $0,03 \mathrm{Ca}$ & $0,85 \mathrm{Aa}$ \\
Pré-embebição em ácido giberélico $100 \mathrm{mg} \mathrm{L}^{-1}$ por $48 \mathrm{~h}$ & $0,74 \mathrm{Aa}$ & $0,75 \mathrm{Aa}$ \\
Pré-embebição em ácido giberélico $200 \mathrm{mg} \mathrm{L}^{-1}$ por $48 \mathrm{~h}$ & $0,59 \mathrm{Aa}$ & $0,51 \mathrm{Ba}$ \\
Pré-embebição em $\mathrm{H}_{2} \mathrm{O}$ por 24 horas & $0,50 \mathrm{Aa}$ & $0,69 \mathrm{Aa}$ \\
Pré-embebição em $\mathrm{H}_{2} \mathrm{O}$ por 48 horas & $0,59 \mathrm{Aa}$ & $0,56 \mathrm{Ba}$ \\
Escarificação mecânica & $0,61 \mathrm{Aa}$ & $0,34 \mathrm{Ca}$ \\
Testemunha & $0,26 \mathrm{Ba}$ & 37,54 \\
CV (\%) & & \\
\hline
\end{tabular}

${ }^{2}$ Médias seguidas pela mesma letra, maiúscula na coluna e minúscula na linha, não diferem entre si pelo teste de Scott-Knott, a 5\% de probabilidade. 
aquecimento e pré-embebição em $\mathrm{H}_{2} \mathrm{SO}_{4}$ ou água fervente apresentaram efeito inibitório sobre a porcentagem de germinação. Em sementes de mucuna-preta, a temperatura de $55^{\circ} \mathrm{C}$ em estufa exerceu efeito positivo na superação da dormência, ao contrário do presente trabalho. É possível que esse efeito positivo tenha ocorrido devido aos tempos utilizados por esse autor, que foram de apenas 16 e 24 horas (Wutke et al., 1995). O emprego de água quente a $80^{\circ} \mathrm{C}$ até esfriar foi eficiente para a quebra da dormência de sementes de Ochroma lagopus SW., Bombacaceae (Barbosa et al., 2004). Pré-embebição de sementes de Leucaena leucocephala em água a $80^{\circ} \mathrm{C}$ por 5 e 15 minutos mostrou-se bastante eficiente (Teles et al., 2000). Os autores verificaram, ainda, que a pré-embebição das sementes em água por 24 e 48 horas não exerceu efeito na germinação, diferindo mais uma vez dos resultados encontrados para a croada. Por outro lado, endocarpos de umbuzeiro (Spondias tuberosa Arruda) pré-embebidos em água por períodos de tempo entre 48 e 144 horas não influenciaram a germinação das sementes (Costa et al., 2001).

O ácido sulfúrico exerce efeito corrosivo no tegumento da semente, o que para muitas espécies é favorável porque, ao alterar a permeabilidade da membrana, o ácido sulfúrico permite que a água, fator essencial à germinação, seja absorvida, dando início ao processo germinativo, além de tornar possíveis as trocas gasosas e a eliminação de resistência mecânica à protrusão da radícula, facilitando a expansão do embrião (Dousseau et al., 2007). Trabalhos realizados utilizando o ácido sulfúrico em sementes de diferentes espécies de outras famílias botânicas evidenciaram aumento na porcentagem de germinação e/ou redução no tempo médio da germinação, mesmo quando o tratamento da semente foi feito por período maior que o testado no presente trabalho.

Sementes pré-embebidas em água destilada por 24 ou 48 horas e ácido giberélico (100 ou $200 \mathrm{mg} \mathrm{L}^{-1}$ ), ou submetidas à escarificação mecânica apresentaram os maiores índices de germinação.

Sementes colocadas para germinar em substratos umedecidos com solução de $\mathrm{KNO}_{3}(0,2 \%)$ apresentaram comportamento similar ao substrato $\mathrm{H}_{2} \mathrm{O}$; porém, na ausência de tratamento (testemunha), o substrato umedecido com $\mathrm{KNO}_{3}$ inibiu a germinação se comparado ao tratamento em que as sementes foram colocadas sobre o substrato umedecido com água. Por outro lado, substrato umedecido com solução de $\mathrm{KNO}_{3}$ a $0,2 \%$ apresentou efeito positivo em sementes tratadas com ácido giberélico em ambas as concentrações analisadas, sendo esses os melhores resultados encontrados no presente trabalho.

Tabela 2 - Germinação (\%) de sementes de Croada (Mouriri elliptica Mart.), submetidas a diferentes métodos de superação de dormência e semeadas em substratos umedecidos com água ou com solução de $\mathrm{KNO}_{3}(0,2 \%)$.

\begin{tabular}{lcc}
\multicolumn{1}{c}{ Métodos de superação de dormência } & \multicolumn{2}{c}{ Substrato } \\
\cline { 2 - 3 } & $\mathrm{H}_{2} \mathrm{O}$ & $\mathrm{KNO}_{3}$ \\
\hline Pré-resfriamento (5 ${ }^{\circ} \mathrm{C}$ por 07 dias) & $46,50 \mathrm{Ba}$ & $56,75 \mathrm{Ca}$ \\
Pré-aquecimento (40 ${ }^{\circ}$ por 07 dias) & $1,75 \mathrm{Ca}$ & $0,00 \mathrm{Ea}$ \\
Pré-embebição em $\mathrm{H}_{2} \mathrm{SO}_{4}$ por 05 minutos & $0,00 \mathrm{Ca}$ & $0,00 \mathrm{Ea}$ \\
Pré-embebição em $\mathrm{H}_{2} \mathrm{SO}_{4}$ por 15 minutos & $0,00 \mathrm{Ca}$ & $0,00 \mathrm{Ea}$ \\
Pré-embebição em água fervente por 05 minutos & $1,75 \mathrm{Ca}$ & $0,00 \mathrm{Ea}$ \\
Pré-embebição em água fervente por 15 minutos & $3,25 \mathrm{Ca}$ & $0,00 \mathrm{Ea}$ \\
Pré-embebição em ácido giberélico $100 \mathrm{mg} \mathrm{L}^{-1}$ por $48 \mathrm{~h}$ & $68,50 \mathrm{Ab}$ & $83,25 \mathrm{Aa}$ \\
Pré-embebição em ácido giberélico $200 \mathrm{mg} \mathrm{L}^{-1}$ por $48 \mathrm{~h}$ & $65,00 \mathrm{Ab}$ & $81,75 \mathrm{Aa}$ \\
Pré-embebição em $\mathrm{H}_{2} \mathrm{O}$ por 24 horas & $63,25 \mathrm{Aa}$ & $65,25 \mathrm{Ba}$ \\
Pré-embebição em $\mathrm{H}_{2} \mathrm{O}$ por 48 horas & $68,25 \mathrm{Aa}$ & $66,75 \mathrm{Ba}$ \\
Escarificação mecânica & $76,75 \mathrm{Aa}$ & $67,00 \mathrm{Ba}$ \\
Testemunha & $45,00 \mathrm{Ba}$ & $41,75 \mathrm{Db}$ \\
CV (\%) & & 25,19 \\
\hline
\end{tabular}

${ }^{2}$ Médias seguidas pela mesma letra, maiúscula na coluna e minúscula na linha, não diferem entre si pelo teste de Scott-Knott, a 5\% de probabilidade. 


\section{CONCLUSÕES}

Sementes de croada germinam mais rápido quando pré-embebidas em ácido giberélico, em substrato umedecido com água ou com solução contendo $\mathrm{KNO}_{3}$ $0,2 \%$; pré-embebidas em água por 24 horas, em substrato umedecido com água ou, independentemente do substrato, imersas em água por 48 horas ou submetidas à escarificação mecânica e colocadas para germinar em substrato contendo água.

Solução contendo ácido giberélico a 100 e $200 \mathrm{mg} \mathrm{L}^{-1}$, em substrato umedecido com $\mathrm{KNO}_{3}$, promove maior porcentagem de germinação de sementes de croada.

\section{AGRADECIMENTOS}

Ao $\mathrm{CNPq}$, pela concessão da bolsa de iniciação científica aos dois primeiros autores, e ao Sr. Arlindo Thomáz da Silva e família, pela doação do material vegetal utilizado no presente trabalho.

\section{REFERÊNCIAS BIBLIOGRÁFICAS}

BARBOSA, A.P.; SAMPAIO, P.T.B.; CAMPOS, M.A.A.; VARELA, V.P.; GONÇALVES, C.Q.B.; IIDA, S.

Tecnologia alternativa para a quebra de dormência das sementes de pau-de-balsa (Ochroma lagopus Sw.; Bombacaceae). Acta Amazônica, Manaus, v.34, n.1, p.107-110, 2004

BORGES, E.E.L.; RIBEIRO JUNIOR, J.I.; REZENDE, S.T.; PEREZ, S.C.J.G.A. Alterações fisiológicas em sementes de Tachigalia multijuga (Benth.) (mamoneira) relacionadas aos métodos para a superação da dormência. Revista Árvore, Viçosa, v.28, n.3, p.317-325, 2004.

BOSCAGLI, A.; SETTE, B. Seed germination enhacement in Satureja montana L. spp. Montana. Seed Science \& Technology, v.29, n.2, p.347-355, 2001.

CARMONA, R.; FERGUSON, J.R.; MAIA, M.S. Germinação de sementes em Stylosanthes macrocephala M. B. Ferr et al. Souza Costa e S. capitata Vog.in Linnaea. Revista Brasileira de Sementes, Pelotas, v.8, n.3, p.19-27, 1986.

COSTA, N.P.; BRUNO, R.L.A.; SOUZA, F.X.; LIMA, E.D.P.A. Efeito do estádio de maturação do fruto e do tempo de pré-embebição de endocarpos na germinação de sementes de umbuzeiro (Spondias tuberosa Arr. Câm.). Revista Brasileira de
Fruticultura, Jaboticabal, v.23, n.3, p.738-741, dez. 2001.

CRUZ, E.D.; CARVALHO, J.E.U.; QUEIROZ, R.J.B. Scarification with sulphuric acid of Schizolobium amazonicum Huber ex Ducke seeds - Fabaceae. Scientia Agrícola, Piracicaba, v.64, n.3, p.308-313, maio/ jun. 2007.

DOUSSEAU, S.; ALVARENGA, A.A.; CASTRO, E.M.; ARANTES, L.O.; NERY, F.C. Superação de dormência em sementes de Zeyheria montana Mart. Ciência e Agrotecnologia, Lavras, v.31, n.6, p.1744-1748, nov./dez. 2007.

EMPRESA BRASILEIRA DE PESQUISA

AGROPECUÁRIA. Relatório técnico anual do Centro de Pesquisa Agropecuária do Cerrado: 1982-1985. Brasília, 1987.

FERREIRA, S.A.N.; GENTIL, D.F.O. Extração, embebição e germinação de sementes de tucumã (Astrocaryum aculeatum). Acta Amazonica, Manaus, v.36, n.2, p.141145, 2006.

HERMANSEN, L.A.; DURYEA, M.L.; WHITE, T.L. Variability in seed coat dormancy in Dimorphandra mollis. Seed Science Technology, v.28, n.3, p.567-580, 2000.

LIMA, J.D.; ALMEIDA, C.C.; DANTAS, V.A.V.; SILVA, B.M.S.; MORAES, W.S. Efeito da temperatura e do substrato na germinação de sementes de Caesalpinia ferrea Mart. ex Tul. (Leguminosae, Caesalpinoideae). Revista Árvore, Viçosa, v.30, n.4, p.513-518, 2006.

LOPES, J.C.; DIAS, P.C.; MACEDO, C.M.P. Tratamentos para acelerar a germinação e reduzir a deterioração das sementes de Ormosia nitida VOG. Revista Árvore, Viçosa, v.30, n.2, p.171-177, 2006.

MARTINS, C.C.; SILVA, W.R. Métodos de superação de dormência de sementes de barbatimão. Acta

Scientiarum Agronomy, Maringá, v.30, n.3, p.381-385, 2008 .

PIVELLO, V.R. Cerrado. Disponível em: <http:// 'mre.gov.br/cdbrasil/itamaraty/webs?. Acesso em: $10 \mathrm{jul}$. 2007 
RIBEIRO JÚNIOR, J.I. Análises estatísticas no SAEG. Viçosa, MG: UFV, 2001. 301p.

SILVA, D.B.; SILVA, A.S.; JUNQUEIRA, N.T.V.; ANDRADE, L.R.M. Frutas do Cerrado. Brasília: Embrapa Informação Tecnológica, 2001. 178p.

TAIZ, L.; ZEIGER, E. Giberelinas: reguladores da altura dos vegetais: fisiologia vegetal.3.ed. Porto Alegre: Artmed, 2004. 488p.
TELES, M.M. et al. Métodos para quebra da dormência em sementes de leucena (Leucaena leucephala (Lam.) de Wit). Revista Brasileira de Zootecnia, Viçosa, v.29, n.2, p.387-391, 2000.

WUTKE, E.B.; MAEDA, J.A.; PIO, R.M. Superação da dormência de sementes de mucuna-preta pela utilização de "calor seco". Scientia Agrícola, Piracicaba, v.52, n.3, p.482-490, 1995. 